\title{
Seasonal distribution of pharmaceuticals in marine water and sedi- ment from a mediterranean coastal lagoon (SE Spain)
}

\author{
R. Moreno-González ${ }^{\mathrm{a}}$, S. Rodriguez-Mozaz ${ }^{\mathrm{b}}, \mathrm{M}$ Gros $^{\mathrm{b}}$, D. Barceló ${ }^{\mathrm{b}, \mathrm{c}}$, V.M. León ${ }^{\mathrm{a}}$ \\ a Instituto Español de Oceanografía, Centro Oceanográfico de Murcia, Apdo. 22, C/ Varadero 1, 30740 San Pedro del Pinatar, Murcia, Spain. \\ ${ }^{\mathrm{b}}$ Catalan Institute for Water Research (ICRA)-Parc Científic i Tecnològic de la Universitat de Girona, Edifici $\mathrm{H}_{2} \mathrm{O}$, Emili Grahit,101, 17003 Girona, Spain. \\ ${ }^{\mathrm{c}}$ Department of Environmental Chemistry, IDAEA-CSIC, C/Jordi Girona 18-26, 08034 Barcelona, Spain.
}

\section{A R T I C L E I N F O}

\section{Article history:}

Received 18 December 2014

Received in revised form

3 February 2015

Accepted 14 February 2015

\section{Keywords:}

Pharmaceuticals

Distribution

Seasonality

Coastal lagoon

Seawater

Sediment

Environmental risk

\begin{abstract}
A B S T R A C T
The seasonal variations in the occurrence and distribution of pharmaceuticals were evaluated in seawater and sediment of Mar Menor lagoon from spring 2010 to winter 2011. A total of 20 pharmaceuticals in seawater and 14 in sediments were found at concentrations from low ng L ${ }^{-1}$ up to $168 \mathrm{ng} \mathrm{L}^{-1}$ (azithromycin) in seawater and from low $\mathrm{ng} \mathrm{g}^{-1}$ up to $50.3 \mathrm{ng} \mathrm{g}^{-1}$ (xylazine) in sediments. Azithromycin, xylazine and metoprolol were the most ubiquitous compounds in seawater since they were found in all seawater samples collected. Seven compounds were quantified in both matrices: clarithromycin, erythromycin, hydrochlorothiazide, irbesartan, losartan, salicylic acid and valsartan. Seasonal distribution profiles revealed different sources of pollutants associated to both, El Albujón watercourse (which receives the input of a WWTP) and other non-controlled discharges, into the lagoon. In summer the highest concentrations in seawater for most of the pharmaceuticals were detected close to main touristic nuclei, probably as consequence of sources such as the excretion from bathers and/or other non-controlled discharges, these being significantly higher than in autumn and winter for antibiotics. On the contrary, the mean concentration of lorazepam was significantly higher in colder seasons than in warmer ones. Sulfamethoxazole, erythromycin and especially clarithromycin showed hazard quotients higher than 1 in seawater at some areas of this lagoon indicating a potential risk to aquatic organisms in such specific areas.
\end{abstract}

(c) 2015 Elsevier Inc. All rights reserved.

\section{Introduction}

The use of pharmaceuticals for both human and veterinary applications is increasing year by year. However, their environmental behaviour has only been studied in the last two decades. Pharmaceuticals access the environment by different ways but their main input is through treated and untreated wastewater discharges, since conventional wastewater treatments are unable to completely remove these pollutants (Gros et al., 2010; Ratola et al., 2012). Consequently their presence in all kinds of continental water bodies such as rivers (Kolpin et al., 2002; Valcárcel et al., 2013), lakes (Tixier et al., 2003; Loos et al., 2007; Daneshvar et al., 2010), marshlands (Vazquez-Roig et al., 2012), reclaimed water (Panditi et al., 2013), groundwater (Stuart et al., 2012), protected wetlands (Camacho-Muñoz et al., 2010; Vazquez-Roig et al., 2011) and even drinking water (Morasch et al., 2010; Valcárcel et al., 2011), has been confirmed worldwide. Because of the discharge of continental water into the sea, some pharmaceuticals

\footnotetext{
E-mail address: victor.leon@mu.ieo.es (V.M. León).
}

will likely end up in the marine receiving environment and thus there is a need to increase our knowledge about their occurrence in such ecosystems. It is only in recent years that some studies have been conducted to evaluate the input of pharmaceuticals in coastal areas (Thomas and Hilton 2004; Moreno-González et al., 2014) in order to understand their fate in the marine environment (Pait et al., 2006; Alfonso-Olivares et al., 2013; Rodríguez-Navas et al. 2013). Some studies have focused on their distribution in seawater (Weigel, 2003; Zhang et al., 2012; Zou et al., 2011; Zheng et al., 2012; Jiang et al., 2014), but only a few have assessed their occurrence and distribution in marine sediments (Li et al., 2012; Stewart, 2013, Shi et al., 2014; Lara-Martín et al., 2014). Although most pharmaceuticals are mainly hydrophilic and tend to be present in the dissolved fraction, some of them can undergo specific interactions with solid fraction and as a result can be transferred to sediments. Since sorption processes are a key factor for the reactivity, mobility, persistence and bioavailability of pollutants in natural waters, there is a need to understand such interactions of pharmaceuticals with sediments and aquatic particles.

The most vulnerable marine environments are coastal areas, 